\title{
Total Clearance Observed Normalized by Body Mass Index
}

National Cancer Institute

\section{Source}

National Cancer Institute. Total Clearance Observed Normalized by Body Mass Index. NCl Thesaurus. Code C92403.

The observed total body clearance for intravascular administration divided by the body mass index. 